\title{
THE DETERMINATION OF SULFHYDRYL GROUPS IN SERUM. II. PROTEIN ALTERATIONS ASSOCIATED WITH DISEASE ${ }^{1}$
}

\author{
By EMANUEL B. SCHOENBACH, NORMAN WEISSMAN, AND ELEANOR B. \\ ARMISTEAD \\ (From the Departments of Preventive Medicine, Medicine, and Physiological Chemistry, The \\ Johns Hopkins University School of Medicine, Baltimore, Md.)
}

(Submitted for publication February 14, 1951, accepted April 23, 1951)

\section{INTRODUCTION}

The status of the serum proteins both in health and disease has been extensively studied in the hope that data might be assembled which would contribute to knowledge of the pathogenesis of many diseases, aid in the classification of the metabolic alterations induced by pathological states, be of use in early diagnosis or differential diagnosis, and serve as a rationale for improved supportive therapy (1). Ever since glutathione was isolated from yeast by Hopkins (2), increasing attention has been devoted to studies of the role played by the sulfhydryl group in enzyme activity (3-6), cell division and growth $(7,8)$ and protein structure (9-11).

Because of the importance of its biochemical associations, an investigation of the sulfhydryl group was undertaken as part of a program for the study of the mechanism of action of various chemical agents on the growth and viability of normal and malignant cells. Blood was selected initially for this study because, $a$ ) to a certain extent, it is in equilibrium with and reflects the status of other body tissues; $b$ ) it has been exhaustively studied; and $c$ ) a uniform sample can be obtained from an individual.

A preliminary study showed that the sulfhydryl content of the serum protein from normal individuals was relatively constant, and the distribution was within a narrow range. The values were reduced when the sera from patients suffering from neoplastic, infectious or metabolic diseases were similarly examined (12). The relationship of the serum protein components to their content of sulfhydryl groups was then examined. The sulf-

1 This investigation was conducted under a grant from the American Cancer Society to the Department of Preventive Medicine, The Johns Hopkins University School of Medicine, recommended by the Committee on Growth of the National Research Council. hydryl content of normal serum, serum albumin, and serum globulin was determined with respect to the total nitrogen and peptide content of these fractions (13). These determinations revealed that normal serum and its fractions could be distinguished by characteristic relationships between the sulfhydryl group and the total nitrogen or the number of peptide bonds in the proteins. The present report will describe similar observations on sera from patients with various diseases.

\section{METHODS AND MATERIALS}

The details for obtaining the serum sample, storage, fractionation, nitrogen analysis, biuret analysis, sulfhydryl determination and calculations have been published (13). In summary, the procedures employed were:

1. Blood was obtained from patients in the fasting state and the serum carefully separated to avoid hemolysis. The serum was either examined in the fresh state soon thereafter or stored at minus $78^{\circ} \mathrm{C}$ until analyzed.

2. The serum was fractionated according to the method of Pillemer and Hutchinson (14).

3. The protein content of the serum and the albumin and globulin components were determined by the Kjeldahl nitrogen and biuret methods. The term $\mathrm{D}$, when employed, refers to the optical density in the biuret method. Electrophoretic analyses were also performed in veronal buffer $\mathrm{pH} 8.6,0.1$ ionic strength, employing a modified Longsworth apparatus. The descending mobility was routinely employed except as noted with individual sera. Components migrating with a mobility of 2.0 to $2.5 \times 10^{-5} \mathrm{~cm}^{2} /$ $\mathrm{sec}^{-1} / \mathrm{volt}^{-1}$ have been designated as M protein. Sera which contained pigment, lipid or other interfering components which rendered them unsuitable for electrophoretic analysis are not included. No attempt was made to remove these interfering substances by filtration, extraction, freezing, etc. They are designated as unsatisfactory samples or not done.

4. The sulfhydryl determinations were made by amperometric titration in $21 \%$ methanol solution containing ammonium nitrate and ammonium hydroxide as supporting electrolytes. The current which flowed between a mercury-mercuric iodide electrode and a rotating platinum electrode was measured with a sensitive galvanometer. Duplicate determinations on individual sera showed less 
than a $2 \%$ variation. The results are expressed as micromoles of sulfhydryl ( $\mathrm{SH})$. One $\mathrm{ml}$. of $.001 \mathrm{~N}$ silver nitrate is equivalent to 1 micromole of $\mathrm{SH}$.

The sulfhydryl content of the serum and its constituents is expressed as follows:

a) The sulfhydryl content of the total protein in $100 \mathrm{ml}$ whole serum or of the albumin and globulin components contained in that volume.

b) The sulfhydryl content per gram of Kjeldahl nitrogen obtained employing whole serum, albumin, or globulin fractions. No correction was made for the serum N.P.N., as among the normals the latter represented approximately $3 \%$ of the total nitrogen and, even in the abnormal states studied, the final values (with few exceptions) were not apparently influenced by such correction.

c) The sulfhydryl content per unit of optical density with a biuret method. This has been utilized to characterize the protein with respect to its peptide content. The total nitrogen determination measures peptide nitrogen, non-peptide amino acid nitrogen such as $\epsilon$ amino, imidazole, or guanidinium nitrogen as well as the non-protein nitrogenous constituents of serum. The quantitative biuret determination is influenced only by the number of nitrogen atoms bound in peptide linkage. Human serum albumin has been found to contain approximately 577 peptide bonds per mole (15). The 586 amino acids probably exist as nine polypeptide chains each of which contains approximately 65 amino acids. These polypeptide chains lie adjacent to each other and are bound to each other by various types of cross linkages, one of which presumably yields the sulfhydryl group when the albumin molecule is titrated amperometrically. We have found that serum albumin from normal individuals contained 0.71 mole of $\mathrm{SH}$ per mole of albumin. This was believed to represent the mean resulting from the presence of a mercaptalbumin containing 1 mole of ( $\mathrm{SH}$ ) sulfhydryl per mole of protein and an albumin molecule containing no amperometrically detectable sulfhydryl (13). We wish to emphasize that it is easier to detect a quantitative change in the single sulfhydryl group per albumin molecule than greater changes in the $\mathbf{5 7 7}$ peptide bonds. Thus, the functional significance of a single sulfhydryl group for enzyme activity may be related to the importance of this group in protein structure (5). For these reasons, it was decided to study the relationship of the sulfhydryl content of the serum proteins with respect to their total nitrogen and peptide content. Electrophoretic analyses provide information with respect to the relative distribution of the recognized major protein components of sera.

\section{RESULTS}

The normal values for the serum protein sulfhydryl content have been presented in detail. No significant difference with respect to age or sex was observed (13). In order to compare the data from patients to be described, a summary of the normal values is presented in Table $I$. The variation among these normal individuals was quite small as indicated by the range and the standard error for these determinations. The results of the preliminary survey of patients' sera are summarized in Table II (12). While the sulfhydryl values differed significantly from the normal, no differential characteristic for the individual groups was apparent.

It was therefore deemed desirable to investigate a group of patients more intensively so as to establish the nature of the sulfhydryl abnormalities observed. Because of individual variation in disease, it did not appear feasible to treat the observations in this series statistically. Each observation will be presented in detail. The data on the various classes of patients whose sera were subjected to such detailed analysis are recorded in Tables IIIVI.

\section{Malignant Tumors}

In Table III, the individual determinations on 11 patients with malignant tumors are presented. The diagnosis in all cases was established by biopsy, operation, and in some cases by autopsy. Nine of the 11 patients had evidence of carcinoma with multiple metastatic involvement. One patient (No. 9) had a rhabdomyosarcoma with pulmonary metastases and one (No. 3 ) had a carcinoma localized to the breast. The sera were obtained more than two months before exitus with the exception of the second specimen from patient 4 , dated $5 / 13 / 49$, and that from patient 10 , dated $7 / 12 / 49$, which were drawn within one week preceding their death.

As may be noted in Table III, and subsequent tables, the total nitrogen content of the serum protein is a poor index of the relative concentrations of albumin and globulin. The total nitrogen content did not deviate markedly from the normal, although the individual albumin and globulin values were distinctly abnormal (col. 4). The albumin content was below normal in the sera of all patients except one (patient 8,12/12/49). The sulfhydryl determination on the unfractionated serum, unlike the total nitrogen values, was reduced in almost all instances (col. 5). The two exceptions were serum obtained on $6 / 8 / 50$ from patient 9 , while in an A-Methopterin induced remission, and the serum from patient 11 with a melanocarcinoma. 
EMANUEL B. SCHOENBACH, NORMAN WEISSMAN, AND ELEANOR B. ARMISTEAD

TABLE I

Summary of normal serum protein and sulfhydryl values

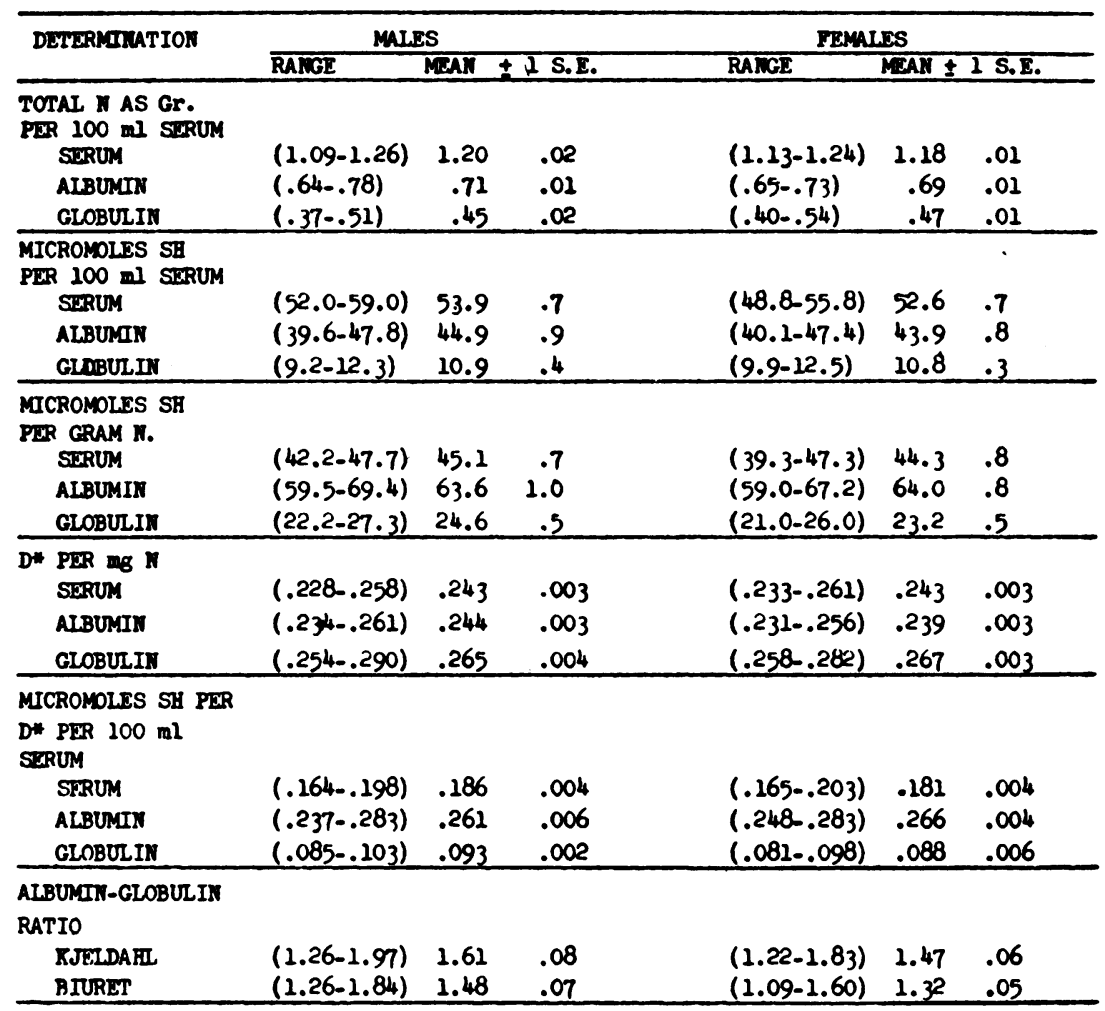

D* = OPTICNL DENSTTY FOR THF BTURET (PLPTIDE) DETERILIATION

TABLE II

Summary of values for serum sulfhydryl in patients with disease

\begin{tabular}{|c|c|c|c|c|c|c|c|}
\hline \multirow[t]{2}{*}{ DIETAET } & \multirow{2}{*}{$\begin{array}{l}\text { BO. OF } \\
\text { DETHRinn- } \\
\text { ATIONS }\end{array}$} & \multicolumn{3}{|c|}{$\mu_{\text {MOLIS SH/200 ml STROU }}$} & \multicolumn{3}{|c|}{ 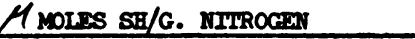 } \\
\hline & & RAIICE & MEAT & 1 S.D. & RAMCE & MEAN : & 1 S.D. \\
\hline 1. CANCER & 46 & $25.3-43.6$ & 35.4 & 2.9 & $22.1-35.6$ & 31.7 & 4.0 \\
\hline 2. IEUSTanta & 34 & $20.4-47.0$ & 37.7 & 5.4 & $\ldots$ & $\cdots$ & $\cdots$ \\
\hline 3. IITECTIOR & 13 & $28.7-50.0$ & 42.6 & 5.2 & $24.2-42.7$ & 34.4 & 5.0 \\
\hline 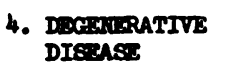 & 22. & $24.0-49.6$ & 40.7 & 7.8 & $21.0-38.0$ & 31.8 & 6.1 \\
\hline 5. MISCELINITSOUS & 312 & $8.6-37.5$ & 22.3 & 7.5 & $8.4-33.5$ & 22.8 & 8.0 \\
\hline
\end{tabular}

1. CARCIMOMA, SARCOM, MEATOCARCIROMA, EIC.

2. IEUKCONIA AND OTHISR IYMPBOMAS.

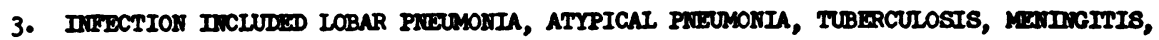
Mastres, ETC.

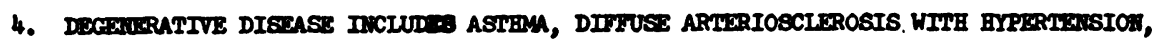
HYPERLROPHIC ARTERITIS, AND COUT.

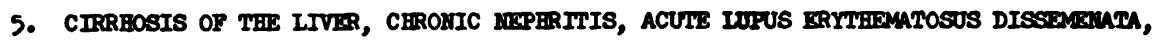

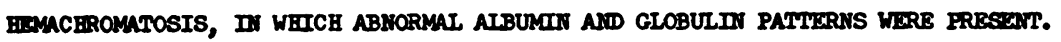




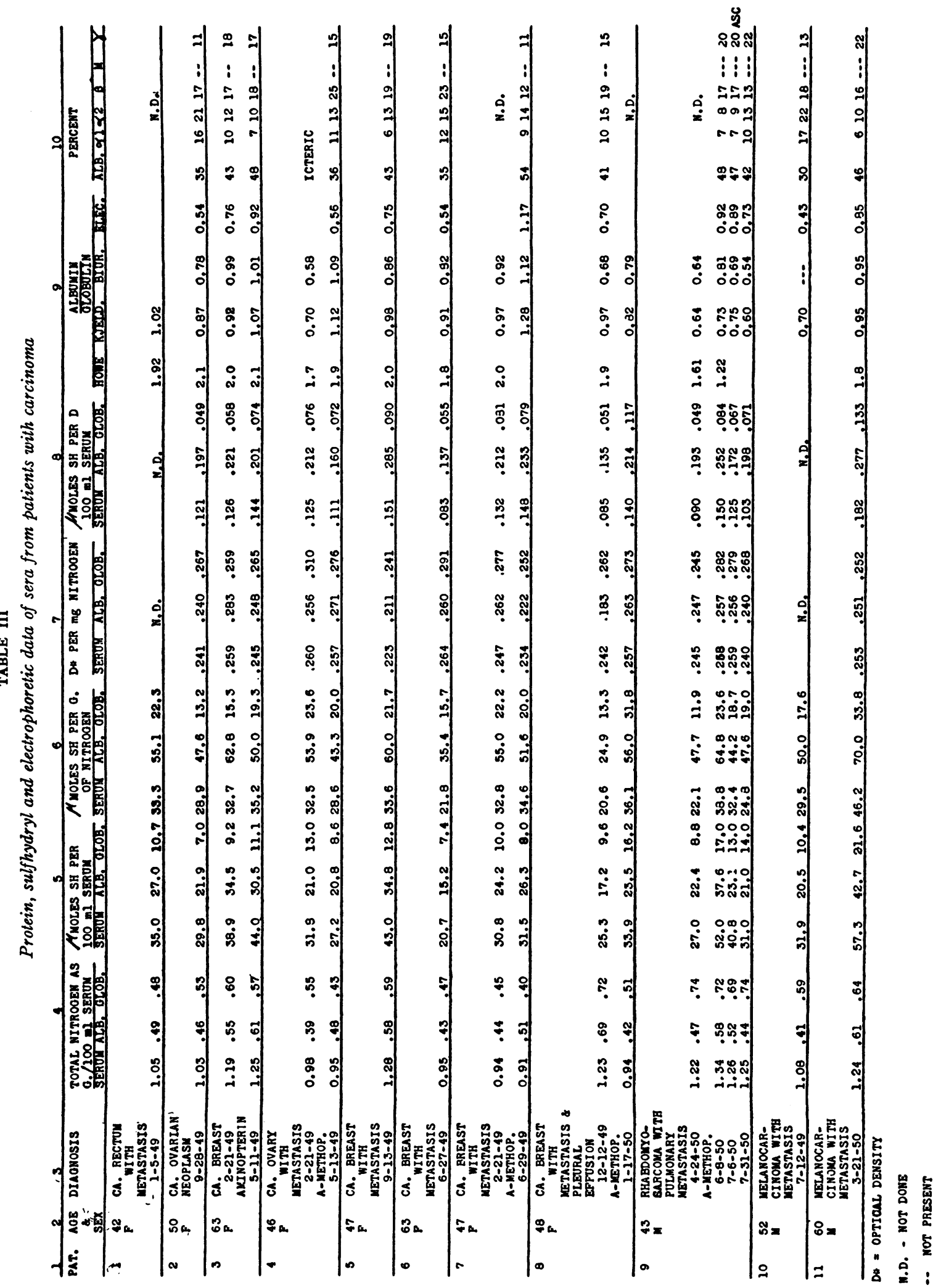



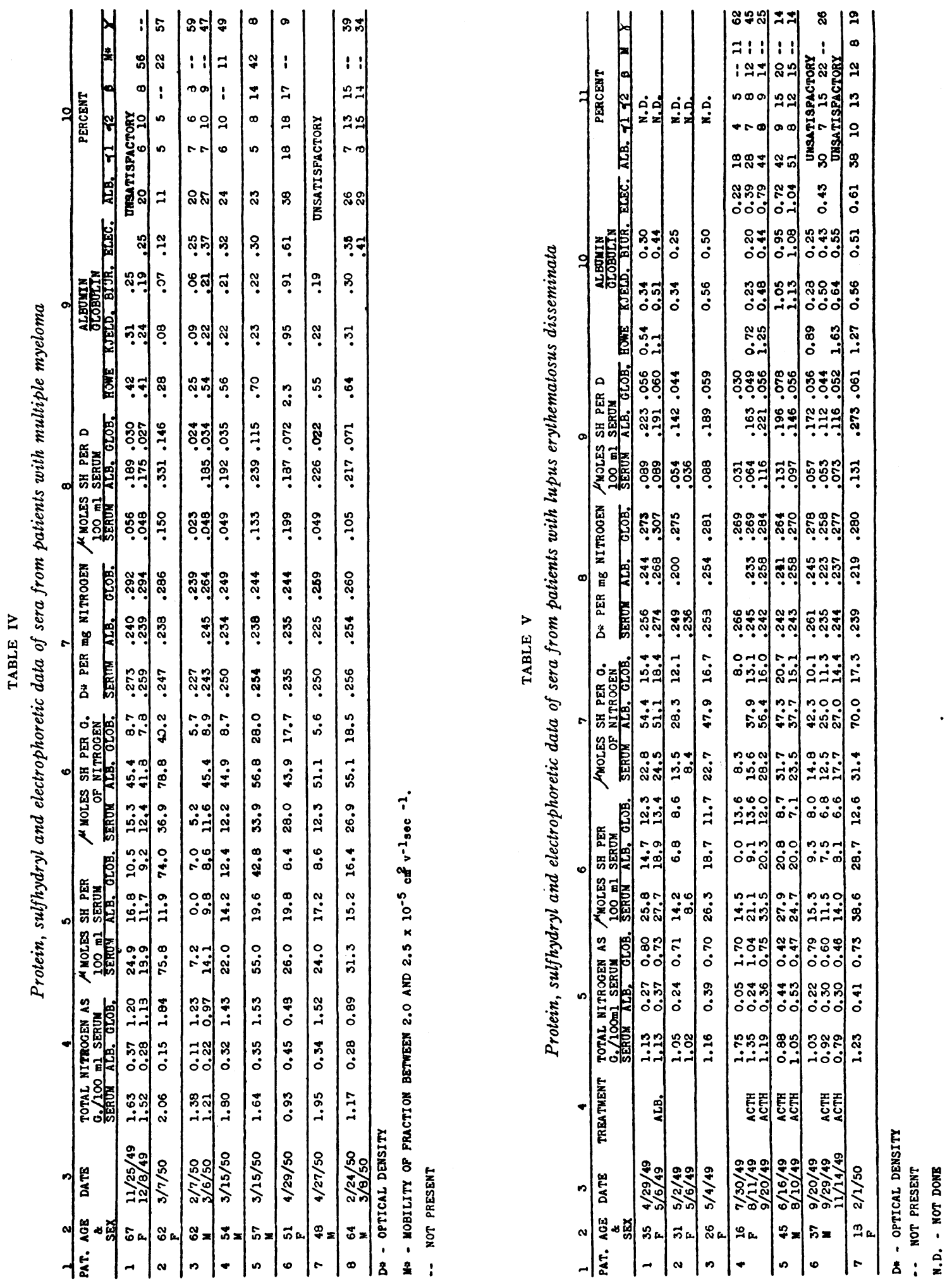


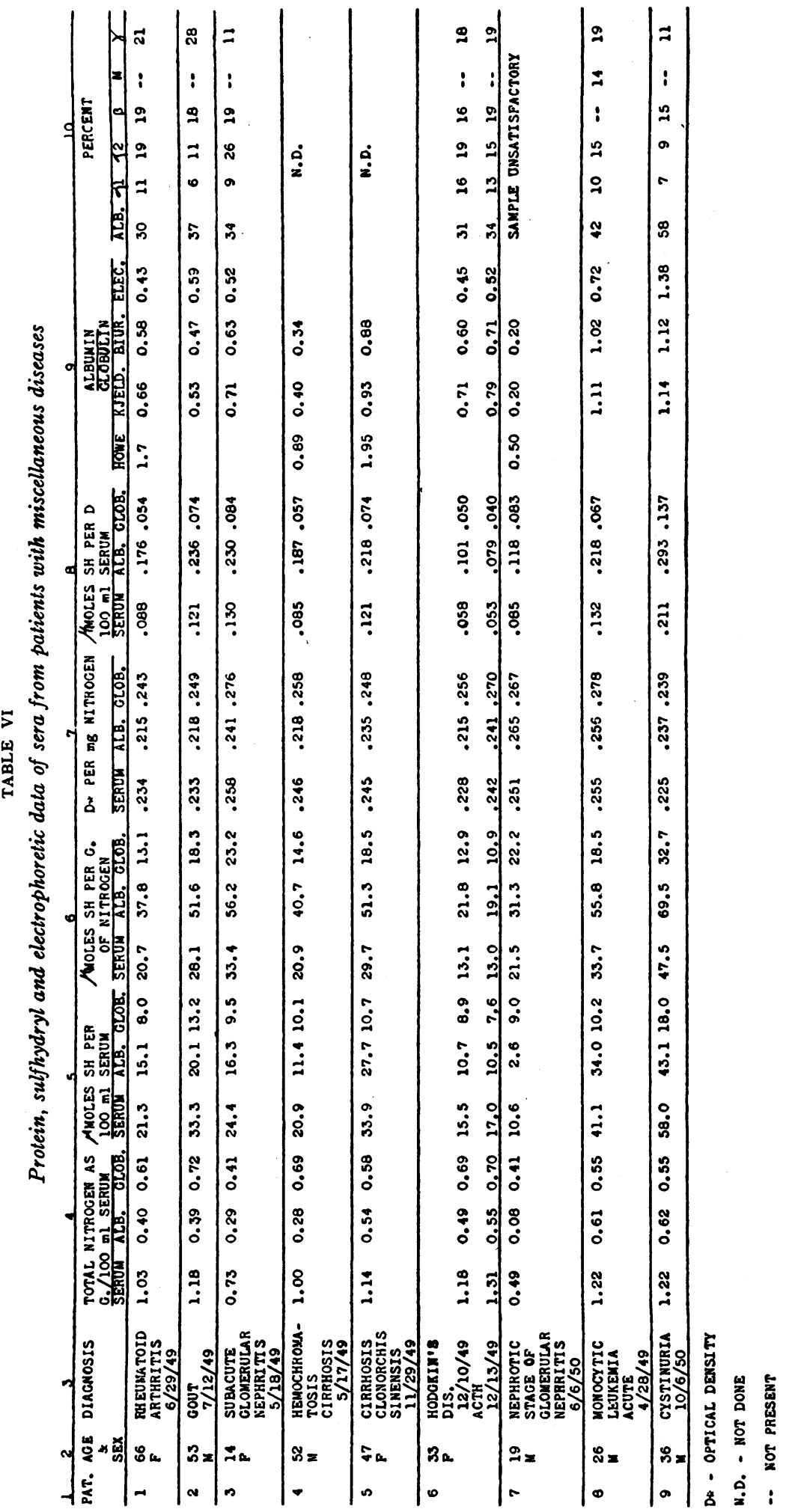


These totals do not reflect the source of the sulfhydryl value since the latter is a resultant of the albumin and globulin values. The only value for the albumin sulfhydryl which was in the normal range was that of patient 11 . The further analysis of the albumin sulfhydryl with respect to micromoles of $\mathrm{SH}$ per gram of nitrogen or peptide unit (cols. 6 and 8; Figure 12) showed that there was a qualitative change in the composition of the serum albumin among many of these patients with malignancy. Most of the values were reduced, three were in the normal range, and one was above normal. When the peptide per mg nitrogen (col. 7 ) in this group was similarly examined, there was no distinctive abnormality noted even among those patients whose $\mathrm{SH}$ (expressed as micromoles per gram nitrogen [col. 6] or per peptide unit [col. 8]) was low. This implied that the protein, with respect to its nitrogen and peptide content, was not significantly different from the normal.

The globulin fraction of the serum as separated by the Pillemer fractionation was normal or increased in this group (col. 4). When the SH per gram of globulin nitrogen was calculated, sera $8 \mathrm{~b}$ and 11 were high, samples $1,4 \mathrm{a}, 7 \mathrm{a}$ and $9 \mathrm{~b}$ approximated normal and the remainder were reduced in a varying degree from the normal (col. 6). When the $\mathrm{SH}$ was expressed per unit peptide, the sera of most patients showed a sub-normal ratio (col. 8). The sera from two patients ( $8 \mathrm{~b}$ and 11 ) showed an increased ratio while in one patient (No. 5), the SH, although low when expressed per gram of nitrogen, was normal when expressed per unit peptide. With the exception of one markedly increased value (patient $4 a$ ), the ratio of peptide per $\mathrm{mg}$ of nitrogen (col. 7) in this group was within the normal range.

Electrophoretic analysis of these sera from patients with malignancy showed no apparent correlation between the sulfhydryl values and the distribution of the serum components. As has been noted in previous studies on sera from such individuals, the albumin component was uniformly reduced while the alpha globulins were usually elevated (16). Among normal individuals, the albumin-globulin ratios obtained by the Pillemer and electrophoretic procedures agreed. When these patients' sera were analyzed, discrepancies were found between the albumin-globulin ratios calculated on the basis of the Pillemer fractionation and the electrophoretic analysis. The differences between ratios determined by the $\mathrm{Kjeldahl}$ and the biuret method were small. Howe protein fractionation of these sera yielded albumin-globulin ratios which were all greater than $1.0(1.5-2.0)$ with only one patient in the low range of 1.2 (Figures 1 and 2).

\section{Multiple Myeloma}

Eight patients with diagnosis of multiple myeloma confirmed by bone marrow aspiration, biopsy and/or autopsy have been studied. Five were males and three were females. Their ages varied from 48 to 67 years. All had evidence of diffuse bone involvement on roentgen examination.

Detailed examination of the sera obtained from these patients is summarized in Table IV. The albumin nitrogen was subnormal in all patients while the globulin was markedly elevated in seven and normal in one. The sulfhydryl content of the serum was markedly reduced in six patients, normal in one, and above normal in another patient (col. 5). The micromoles of albumin sulfhydryl were reduced far below normal in all and nondetectable in one case (col. 5). The globulin $\mathrm{SH}$ varied from subnormal to markedly increased values. The micromoles of SH per gram of protein nitrogen (col. 6) were low in the sera of all patients. With a single exception (patient 2), the same was true of the albumin $\mathrm{SH}$ per gram of nitrogen. The $\mathrm{SH}$ per gram of globulin nitrogen was reduced in six and above normal in two instances (Nos. 2 and 5). These same relationships were noted for the $\mathrm{SH}$ per unit of albumin and globulin peptide (col. 8). No characteristic change in the two sera with high $\mathrm{SH}$ values was observed when the peptide per $\mathrm{mg}$ of nitrogen of the albumin and globulin. components was examined (col. 7).

One serum (No. 2), with a high $\mathrm{SH}$ per gram nitrogen or per peptide unit in both albumin and globulin fraction, appeared to differ on this determination from the other cases in this group. Its electrophoretic pattern was characterized by an extremely low albumin content and a globulin fraction which contained $22 \%$ of the total protein as $\mathrm{M}$ protein and $57 \%$ as gamma globulin. However, this electrophoretic distribution was not markedly different from that of other sera in this series, the sulfhydryl values of which were low. 


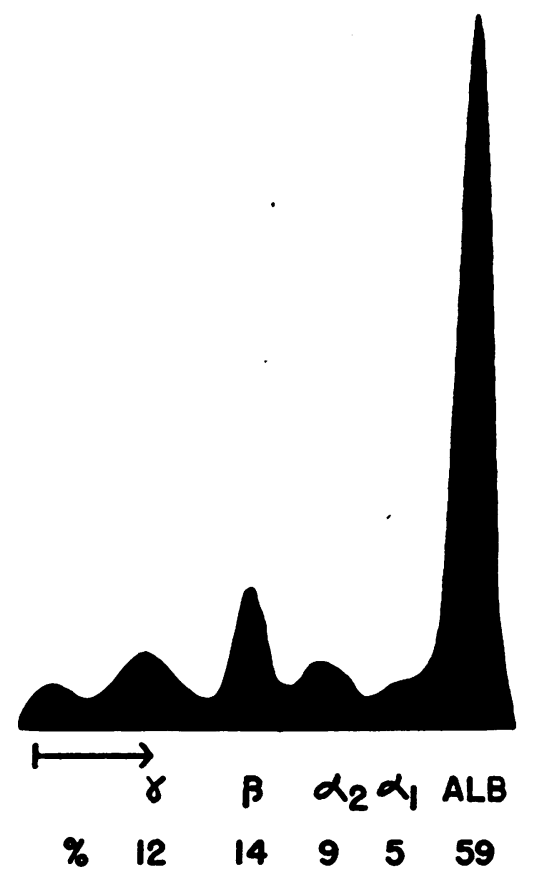

Fig. 1. Normal Electrophoretic Pattern Obtained with the Apparatus and Method Described

(Current-15.2 milliamps., time-9,960 seconds)

It is of interest to note that of seven patients whose sera were analyzed electrophoretically, the sera of four showed the presence of $M$ protein. The serum of one of these four patients contained no gamma globulin. The sera of six of the seven

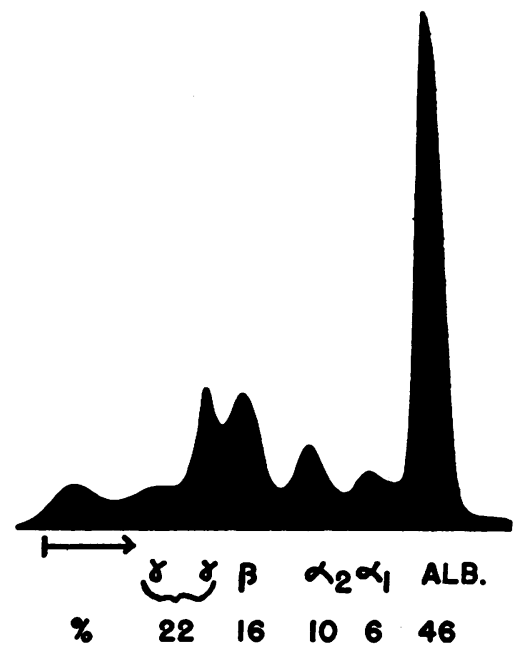

Fig. 2. Patient 11, Table III-Melanocarcinoma with Elevated Sulfhydryl Values in the Protein Components

(Current-15.1 milliamps., time-10,800 seconds)

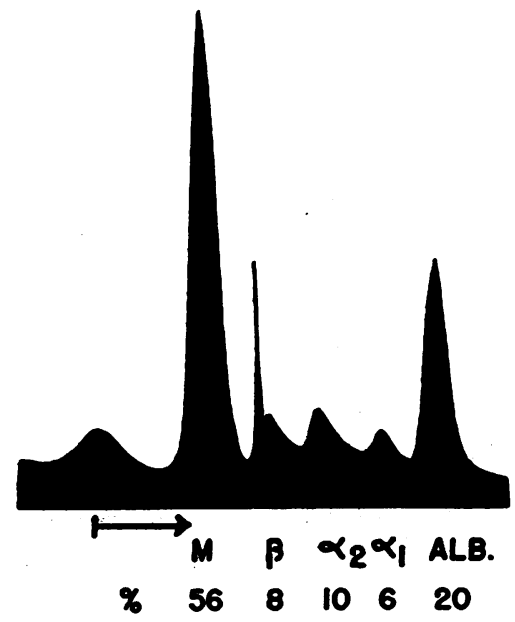

Fig. 3. Patient 1, Table IV, Serum 12/8/49-Multiple Myeloma with M Protein

(Current-15.1 milliamps., time-10,800 seconds)

patients showed a high proportion of either $\mathrm{M}$ protein or gamma globulin. The serum of patient 6 , which did not show a high content of $\mathrm{M}$ protein or gamma globulin, was found to have sulfhydryl values for albumin and globulin which were in the low range (Figures 3-5).

The ratio of albumin to globulin was low in the

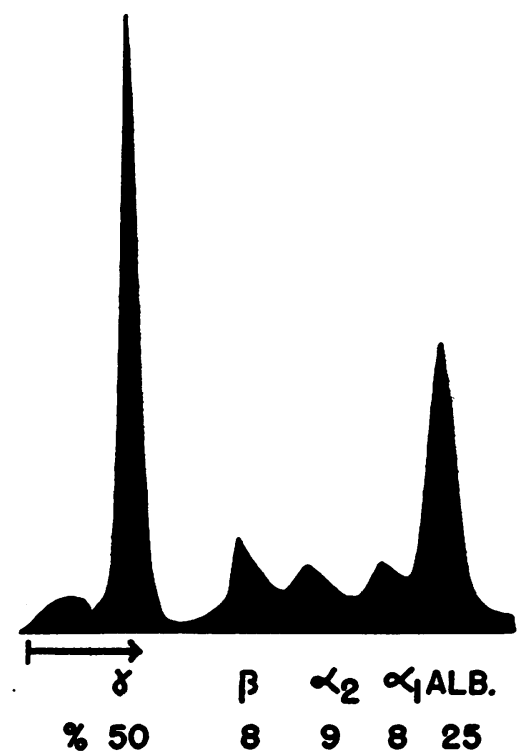

Fig. 4. Patient 3, Table IV, Serum 3/3/50-Multiple Myeloma with Increased Gamma Component

Note similarity to that of $3 / 6 / 50$ in Table IV (not illustrated). (Current-15.0 milliamps., time-9,000 seconds) 


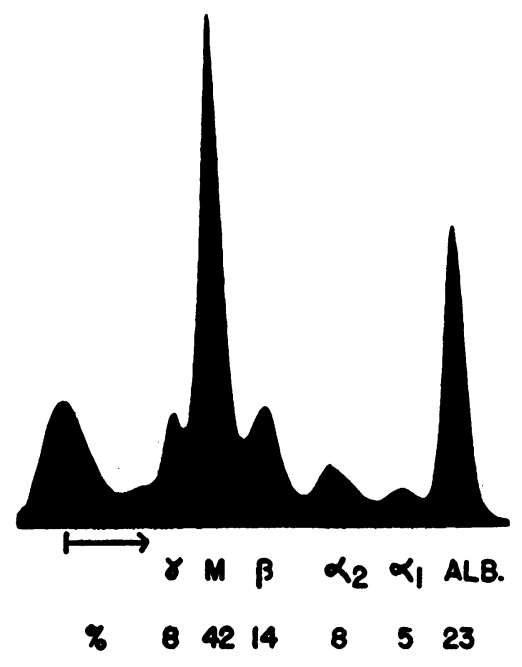

Fig. 5. Patient 5, Table IV, Serum 3/15/50-Multiple Myeloma with Both M and Gamma Components

(Current-15.1 milliamps., time-10,800 seconds)

sera from all patients by all four methods of comparison. The only possible exception was the serum of patient 6 in which the ratio with the Howe method was normal. Its electrophoretic pattern showed a reduction in the gamma globulin, absence of $\mathrm{M}$ protein and high $\alpha_{1}$ and $\alpha_{2}$ globulin components.

Patient 2, with multiple myeloma, had a localized tumor in a vertebra which was removed free of bone or other tissue at autopsy and frozen immediately. After this tumor had been ground in a Waring Blendor at $0^{\circ} \mathrm{C}$, and extracted with 0.14 $\mathrm{M}$ saline, the suspension was clarified by centrifugation at $13,000 \mathrm{rpm}$ at $0^{\circ} \mathrm{C}$ and filtered through a coarse sintered filter. Analysis of this extract showed a nitrogen content of $1.5 \mathrm{mg}$ per $\mathrm{ml}$. The sulfhydryl content of this extract was .19 micromole per $\mathrm{ml}$ or 127 micromoles of $\mathrm{SH}$ per gram nitrogen. The $\mathrm{SH}$ per peptide unit was 0.328 micromole. This latter value equaled the value 0.331 for micromoles of $\mathrm{SH}$ found in the patient's serum albumin. Electrophoretic analysis of this tumor extract showed a pattern of peaks which resembled somewhat the serum pattern in distribution and mobility - albumin 14\%, alpha $16 \%$, alpha $_{2} 9 \%, \mathrm{M}$ protein $4.0 \%$ and gamma globulin $57 \%$. The high SH per gram of nitrogen observed with this extract as well as the increase in the ratio of peptide to total nitrogen (0.387) probably reflects the presence of intracellular protein com- ponents whose amino acid composition differed from the proteins observed in serum.

\section{Lupus Erythematosus}

Seven patients diagnosed as suffering from lupus erythematosus disseminata were selected for study because of the abnormality frequently observed in the serum proteins in this disease, and our previous experience which had indicated that the total serum sulfhydryl content was markedly reduced in this condition. The cases selected for further study had shown clinical and laboratory observations characteristic of the disease. Five patients were females and two were males. Their ages ranged from 16 to 37 . The observations on these patients with lupus erythematosus are summarized in Table V. The serum proteins were altered with a low albumin and normal or high globulin content in all instances (col. 5). The total serum sulfhydryl was below normal in all patients including those specimens obtained while the patient was receiving ACTH (col. 6). The albumin sulfhydryl per $100 \mathrm{ml}$ serum was low in all sera (col. 6) and the serum of only one patient (No. 7) had a normal sulfhydryl per gram of albumin nitrogen (col. 7). The globulin sulfhydryl per $100 \mathrm{ml}$ of serum varied from normal to subnormal and none were normal when expressed per gram globulin nitrogen (col. 7). The same relationships were observed when the sulfhydryl analysis per peptide unit was calculated for both the albumin and globulin components. The peptide to nitrogen ratio of the total serum proteins and albumin did not show any singular deviation although this ratio for the globulins was distinctly skewed toward a higher value (col. 8). As may be noted, although albumin-globulin ratios were diminished, the extent varied with the technique employed (col. 10).

\section{Miscellaneous Disease}

A group of patients was observed with miscellaneous diseases, in many of which abnormalities in serum proteins have been noted. The clinical entities, ages and observations on this group are summarized in Table VI. The albumin nitrogen was reduced in the sera of all these patients while the globulin nitrogen was normal or increased. The amount of albumin present (col. 4) and the 
sulfhydryl detected in this fraction (col. 5) in the serum of patient 7 , was so low that the derived ratio is of questionable significance. With the exception of the cystinuric patient (No. 9), the sulfhydryl content per $100 \mathrm{ml}$ serum in this group was below the normal. This was also true of the $\mathrm{SH}$ in the albumin fraction. No consistent change, except for the high value for patient 9 , was noted in the globulin sulfhydryl (col. 5). The sulfhydryl of the globulin, per peptide unit, in the sera of the two nephrotic patients approximated the normal value and that for the cystinuric patient was above the normal range (col. 8). The peptide content per unit nitrogen in the serum proteins showed no consistent deviation from the normal (col. 7). The sulfhydryl per peptide unit was below normal for all the albumin and globulin samples, with the exception of the patient with cystinuria. The heterogeneity of this group of patients does not permit generalization of these data.

\section{EFFECT OF THERAPY}

The effect of various therapeutic measures on the serum sulfhydryl value could be observed among several patients in these disease groups. One patient (No. 1, Table V) received 125 grams of intravenous salt free human albumin ${ }^{2}$ during the period between the two serum samples which were examined. The albumin nitrogen of the serum rose from 0.27 to 0.37 gram per $100 \mathrm{ml}$ and the globulin fell from 0.80 to 0.73 gram of nitrogen per $100 \mathrm{ml}$ of serum. The sulfhydryl content of the albumin and globulin fractions rose from 14.7 to 18.9 and 12.3 to 13.4 micromoles of $\mathrm{SH}$ per $100 \mathrm{ml}$ of serum respectively. However, the sulfhydryl for albumin decreased from 54.4 to 51.1 micromoles $\mathrm{SH}$ per gram nitrogen and from 0.223 to 0.191 micromole $\mathrm{SH}$ per peptide unit. The $\mathrm{SH}$ per unit globulin nitrogen and per unit globulin peptide rose during this period although the globulin content decreased. The total serum pro-

\footnotetext{
$2 \mathrm{We}$ have examined a similar preparation of human serum albumin for parenteral use (without preservative and salt poor). It was prepared by E. R. Squibb and Co., from plasma collected by the Red Cross (control No. 3024-2). The solution was clear and was stated to contain $25 \%$ albumin. Our studies showed that it contained $42 \mathrm{mg}$ nitrogen per $\mathrm{ml}$ and the optical density by the biuret method was 9.83 per $\mathrm{ml}$. The $\mathrm{SH}$ values were 15.7 micromoles per gram of nitrogen. The D per $\mathrm{mg}$ of nitrogen was .234 and the $\mathrm{SH}$ per D was .067 .
}

tein nitrogen remained unchanged but the components shifted as indicated by the albumin- globulin ratios before and after albumin therapy. These observations are of interest because the albumin administered contained only 15.7 micromoles $\mathrm{SH}$ per gram of nitrogen instead of the normal 63.6 micromoles.

Serum was obtained from four patients receiving ACTH, prior to and during the period of therapy. The data are presented in Table $\mathrm{V}$ (patients 4-6) and Table VI (No. 6). The first patient (Table V, No. 4) was a 16 year old female suffering from acute disseminated lupus. She had received $900 \mathrm{mg}$ of ACTH (Armour), over a period of 11 days, with objective clinical improvement. Her serum showed a rise in the albumin component with a decrease in the gamma globulin and disappearance of the $\mathrm{M}$ component. A fraction, with the mobility of $\beta$ globulin, which had previously been absent, appeared. The total sulfhydryl of the serum rose, and, whereas the albumin sulfhydryl had been zero, the subsequent determination showed 37.9 micromoles of $\mathrm{SH}$ per gram of albumin nitrogen. During the next two week period, she received an additional $677 \mathrm{mg}$ of ACTH. Serum obtained one month later showed progressive changes toward a more normal protein distribution electrophoretically. The sulfhydryl content of the albumin and globulin fractions per unit nitrogen and per unit peptide rose but did not attain the normal value. The serum showed a total protein content within the normal range as a result of the reduction in the globulin content and increase in the albumin. The albumin-globulin ratio was still markedly abnormal (Figures 6 and 7).

The second patient (Table V, No. 5) was diagnosed as having lupus erythematosus disseminata. He had received $480 \mathrm{mg}$ of $\mathrm{ACTH}$ in daily amounts of 40 to $100 \mathrm{mg}$ for the first seven days. ACTH therapy was continued with progressively smaller daily doses of $36,21,15$, and $9 \mathrm{mg}$ during the ensuing month. Sera were obtained for study five days after the ACTH therapy was instituted and a month later while he was in remission and receiving maintenance doses of the hormone. In this period, the total protein nitrogen had increased from 0.88 gram to 1.05 grams per $100 \mathrm{ml}$ serum. The albumin fraction which was 0.44 gram initially 


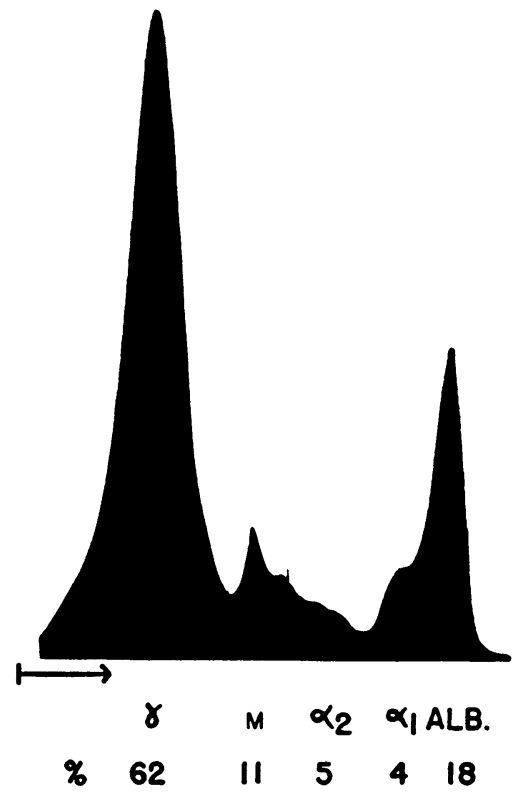

Fig. 6. Patient 4, Table V, Serum 7/30/49-Lupus Erythematosus Before ACTH Administration

No albumin sulfhydryl was detected. (Current-15.1 milliamps., time-9,660 seconds)

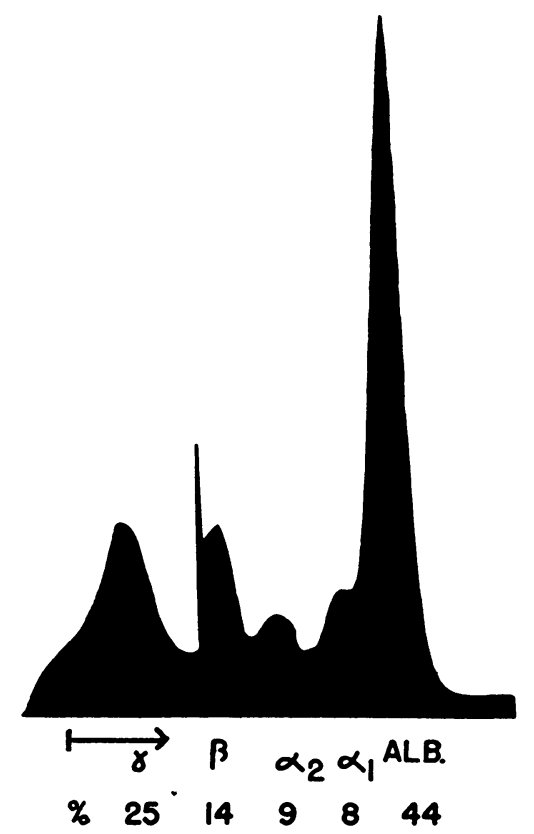

Fig. 7. Patient 4, Table V, Serum 9/20/49-Patient Had Received ACTH

Serum albumin sulfhydryl approximately normal. (Current-15.1 milliamps., time-7,200 seconds) rose to 0.53 gram of nitrogen per $100 \mathrm{ml}$ and the globulin which had been 0.42 gram of nitrogen per $100 \mathrm{ml}$ of serum was 0.47 gram on the later specimen. The total sulfhydryl of the serum proteins decreased somewhat due to a slight fall in both the albumin and globulin content. The fall in $\mathrm{SH}$ was even more apparent in the albumin and globulin $\mathrm{SH}$ components when the $\mathrm{SH}$ per gram nitrogen or per peptide unit was measured (cols. 7 and 9, Table V). Despite the improvement in the albumin content of the serum and in the electrophoretic analysis, the sulfhydryl values were lower and did not parallel the changes in the protein values.

A 37 year old male suffering from acute disseminated lupus (Table $\mathrm{V}$, No. 6) received $100 \mathrm{mg}$ of ACTH daily for eight days and thence $985 \mathrm{mg}$ in varying daily dosage for the following 38 days. He developed a bacteremia during this period and staphylococci of both aureus and albus types were isolated from his blood. Two to 3 grams of aureomycin per day were administered for the first two weeks and for the following two months he received 4.5 grams of aureomycin daily. Specimens of serum from this patient were obtained just preceding and nine days after the initiation of ACTH therapy. Another specimen was obtained during the period that both aureomycin and ACTH were being administered. During the first period while he was receiving $\mathrm{ACTH}$, a fall in the total serum protein was observed with a slight increase in the albumin content and decrease in the globulin. The sulfhydryl in the albumin decreased and that in the globulin increased per gram of nitrogen or per peptide unit (cols. 7 and 9). During the following period when aureomycin was administered together with the ACTH because of the bacteremia, the albumin remained unchanged at its low level, but the globulin nitrogen decreased to the normal level. The albumin sulfhydryl remained unchanged while the globulin sulfhydryl per gram of nitrogen continued to increase. It may be noted that the ratio of albumin to globulin was persistently abnormal in this patient's sera.

The fourth patient (Table VI, No. 6) was a 33 year old female with Hodgkin's disease. She had received $300 \mathrm{mg}$ of $\mathrm{ACTH}$ over a period of three days. During this period a dramatic improvement in her clinical status had occurred. The patient 
became afebrile within 24 hours and had a diuresis with the loss of $13 \mathrm{lbs}$. in body weight. No essential change in the protein or sulfhydryl content of the serum occurred. Ten other patients with lupus, rheumatic fever or rheumatoid arthritis were treated with ACTH for short periods of time. The total serum sulfhydryl as well as serum protein determinations were performed on samples obtained before and during this therapy. In general, a slight decrease in the serum protein nitrogen was observed with a concomitant small increase of sulfhydryl per gram of nitrogen. These unfractionated samples cannot be critically evaluated and the changes observed probably represent a slight increase in the albumin fraction with a decrease in the globulin content of the serum.

Among the patients with malignant tumors (Table III) there were several from whom serial specimens of serum were obtained while they had been receiving folic acid antagonist therapy, either Aminopterin or A-Methopterin. Patients 1, 2, 4,6 , and 7 had shown no objective or apparent clinical response to the therapy. One patient (No. 3) showed local regression of an ulcerated carcinoma of the breast. Two patients (Nos. 8 and 9) manifested temporary regression of the metastatic lesions and clinical improvement. The latter two patients showed a definite change in the sulfhydryl of the serum proteins during this period. Patient 8 had pleural metastases from a carcinoma of the breast with recurrent sanguinous effusions in which carcinoma cells had been observed. She received 5 to $15 \mathrm{mg}$ of A-Methopterin daily, and, after three weeks, $x$-ray examination of the chest showed almost complete clearing of the pleural fluid. Reaccumulation of the fluid was not observed during the ensuing four months of observation. She gained weight and was asymptomatic. From the time just preceding A-Methopterin therapy to the time one month later when A-Methopterin was discontinued prior to discharge from the hospital, the total protein in the serum had decreased with a diminution of both albumin and globulin components. The sulfhydryl per gram albumin or globulin nitrogen more than doubled during the interval. The micromoles of sulfhydryl per peptide unit increased from .135 to .214 for the albumin fraction and from .051 to .117 for the globulin. The second patient (No. 9) had a rhabdomyosarcoma of the left leg with pulmonary metastases. Amputation of the leg had been performed one year previous to this hospital admission. He had lost 20 lbs. in weight, had a paroxysmal cough and drenching night sweats from January through April, 1950. A-Methopterin, $10 \mathrm{mg}$ daily, was administered and within two weeks distinct clinical improvement was noted which was progressive so that the patient left the hospital and felt well enough to attend to his business. X-ray examination of the chest had shown disappearance of some of the pulmonary shadows and diminution in the size of other shadows. The patient had gained 14 lbs. in weight. A-Methopterin had been reduced to $5.0 \mathrm{mg}$ orally per day. One month later, an increase in the size of the pulmonary metastases was noted by roentgen examination with subsequent return of symptoms. These were progressive despite increase in dosage of A-Methopterin to $10 \mathrm{mg}$ per day so that he was rehospitalized. Sera obtained before and during this period of folic acid antagonist therapy showed changes in the sulfhydryl content which paralleled the clinical observations to some extent. Preceding the folic acid antagonist therapy, an increased globulin and low albumin content of the serum was present. The sulfhydryl content of these fractions was low. During the period of clinical improvement, the albumin nitrogen of the serum increased with no apparent change in the globulin. The sulfhydryl increased in both albumin and globulin fractions, to the normal range, when expressed either as micromoles per gram of nitrogen or per peptide unit. With clinical relapse, although still receiving A-Methopterin, the albumin nitrogen of the serum decreased, but the globulin appeared to remain unchanged. The sulfhydryl, per gram albumin nitrogen or peptide unit, decreased rapidly to the original pre-therapy level. The globulin sulfhydryl also decreased. Electrophoresis of these serum samples showed that a decrease in the albumin component occurred during this relapse with an increase in the alpha globulin. The folic acid antagonists do not appear to affect the globulin fraction of the serum in a manner comparable to the uniform decrease observed with ACTH (Figures 8 and 9). 


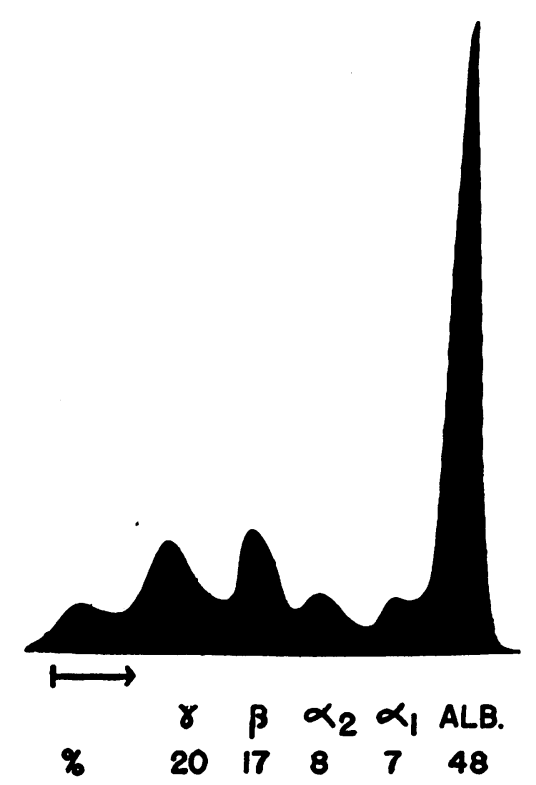

Fig. 8. Patient 9, Table III-Serum Sample Obtained on 6/8/50 when Patient was in a Clinical Remission While Receiving A-Methopterin

(Current-15.2 milliamps., time-10,800 seconds)

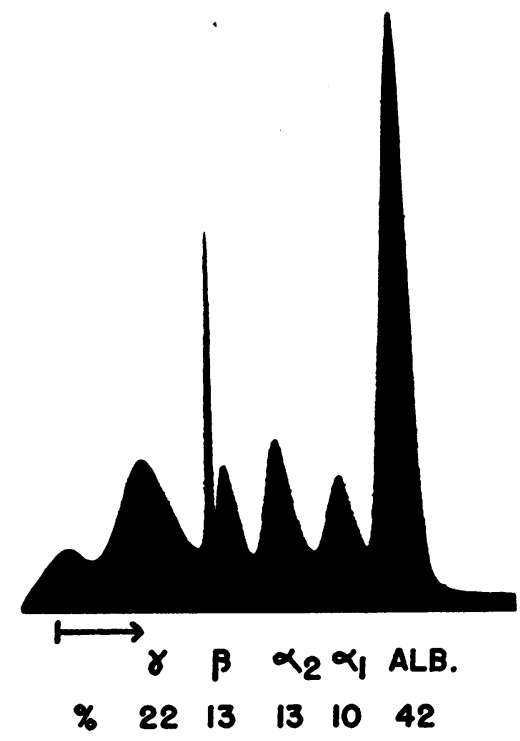

Fig. 9. Same Patient as Figure 8-Serum Sample Obtained on 7/31/50 during Clinical Relapse (Current-15.1 milliamps., time-9,000 seconds)

\section{DISCUSSION}

Kolthoff and Lingane have summarized the results of polarographic studies of blood, based on the presence or absence of sulfhydryl groups (17). Black (18) has reported alterations from the normal in the sulfhydryl content of plasma and serum, from patients with neoplastic disease, as measured by the rate of reduction of methylene blue and other dyes. Glass (19) and Huggins and his colleagues (20) have studied the coagulation of the serum proteins as an index of their albumin content. They have also presented observations indicating that when an alkylating agent such as iodoacetic acid is added to serum, presumably reacting with sulfhydryl groups, the results confirmed the defect noted in various pathologic states when simple coagulation was employed (21).

From the observations reported in the present paper, it is apparent that a reduction in the total sulfhydryl in the serum proteins frequently occurs in various diseased states. Fractionation of the serum and determination of the sulfhydryl in each fraction showed that the total value for the serum protein sulfhydryl was the resultant of those obtained for the albumin and globulin fractions. The sera of normal individuals contain approximately two and one half times as much $\mathrm{SH}$ per gram of albumin nitrogen as per gram globulin nitrogen (13). A reduction in the albumin nitrogen will therefore usually result in a lowered total serum protein sulfhydryl even when an increase in the globulin component occurs. In the majority of the patients studied, the sulfhydryl per gram of albumin or globulin nitrogen in the sera was reduced, and despite marked elevation of the globulin content in various diseases, the total $\mathrm{SH}$ of the serum was rarely normal or above the normal.

The deviations from the normal in the sera are graphically presented in Figures 10-12.

As previously noted (see Methods), the qualitative nature of a protein may be established by several indices. One index would be the number of peptide bonds per $\mathrm{mg}$ of nitrogen. This is a function of the types of amino acids present in the protein. In Figure 11, the results of such an analysis are presented. It will be noted that the results with the sera from these patients show a distribution about the normal. A second index that may be employed is the relationship between the number of sulfhydryl groups per unit of protein nitrogen or peptide $\left(\frac{\mathrm{SH}}{\text { nitrogen }}\right.$ or $\left.\frac{\mathrm{SH}}{\mathrm{D}}\right)$. These values characterize the protein with respect to a specific type 
relationship of albumim to globulin mitrogen and SH VALUES amomo

PATIEMTS WITH DISEASE
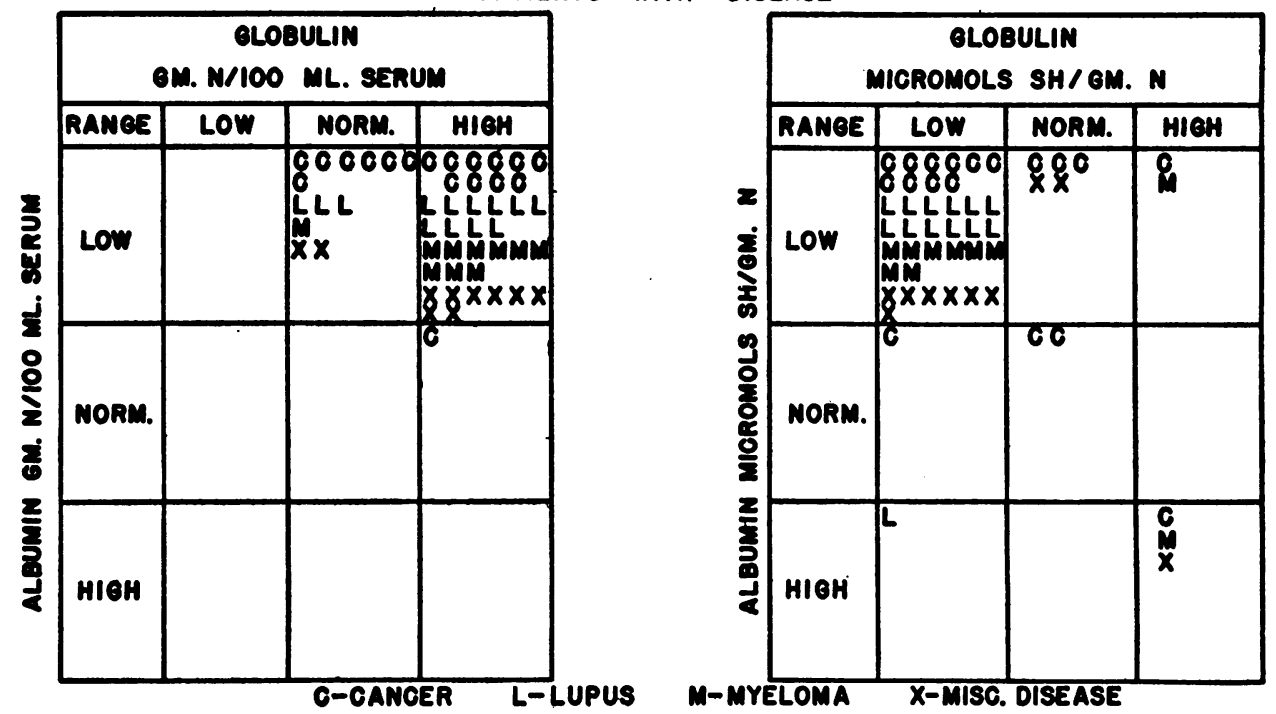

Fig. 10. Distribution of Albumin and Globulin Nitrogen and Albumin and Globulin SH per Gram Protein Nitrogen in Patients with Disease

of linkage other than the peptide bond common to proteins and polypeptides. In Figure 10, the $\mathrm{SH}$ per gram of albumin and globulin nitrogen is represented. Eighty-six \% of the albumin values and $76 \%$ of the globulin values were below the nor- mal range. The $\mathrm{SH}$ per peptide unit, presented in Figure 11, shows that $87 \%$ of the albumin and $79 \%$ of the globulin determinations were subnormal. Seventy-five $\%$ of all the sera examined from these patients was subnormal in both albu-

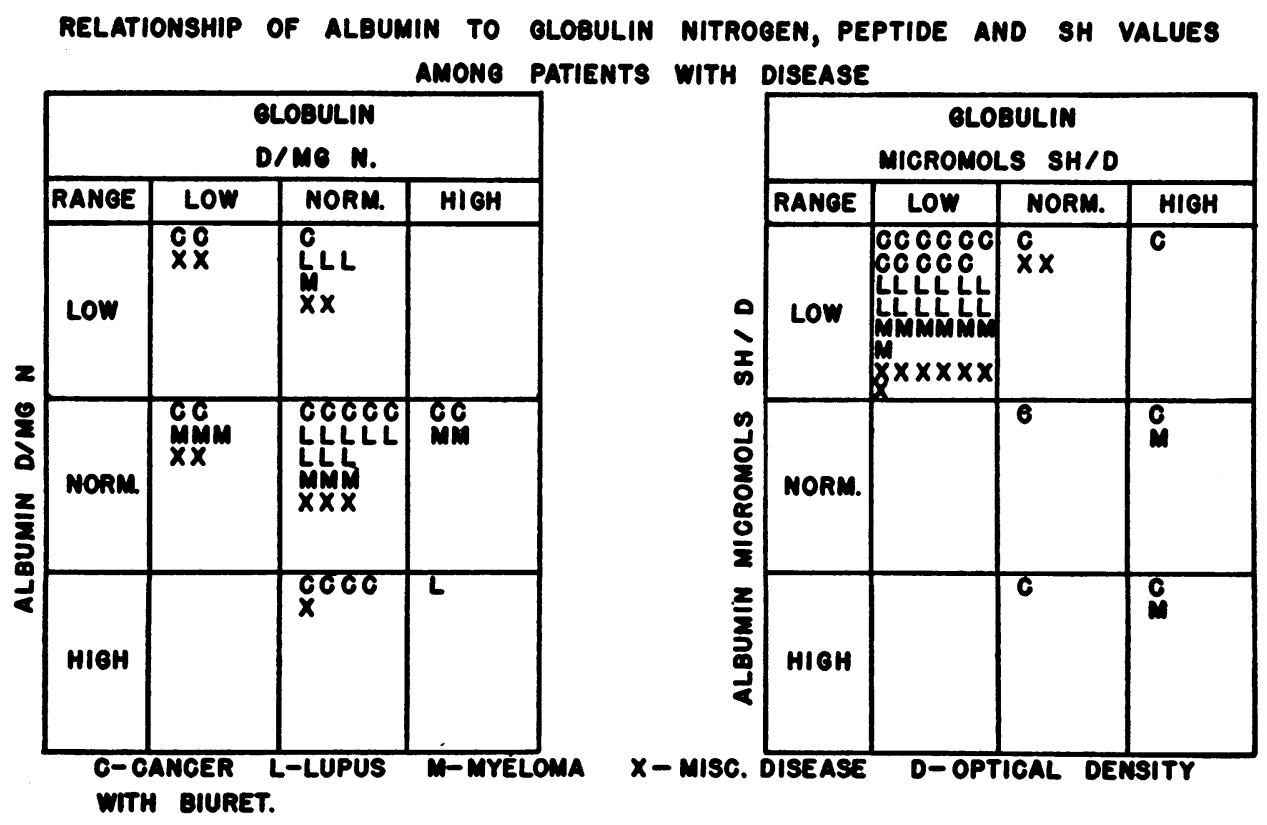

Fig. 11. Peptide per Mg Nitrogen in the Albumin and Globulin Components and the SH per Peptide Unit for these Fractions among Patients with Disease 


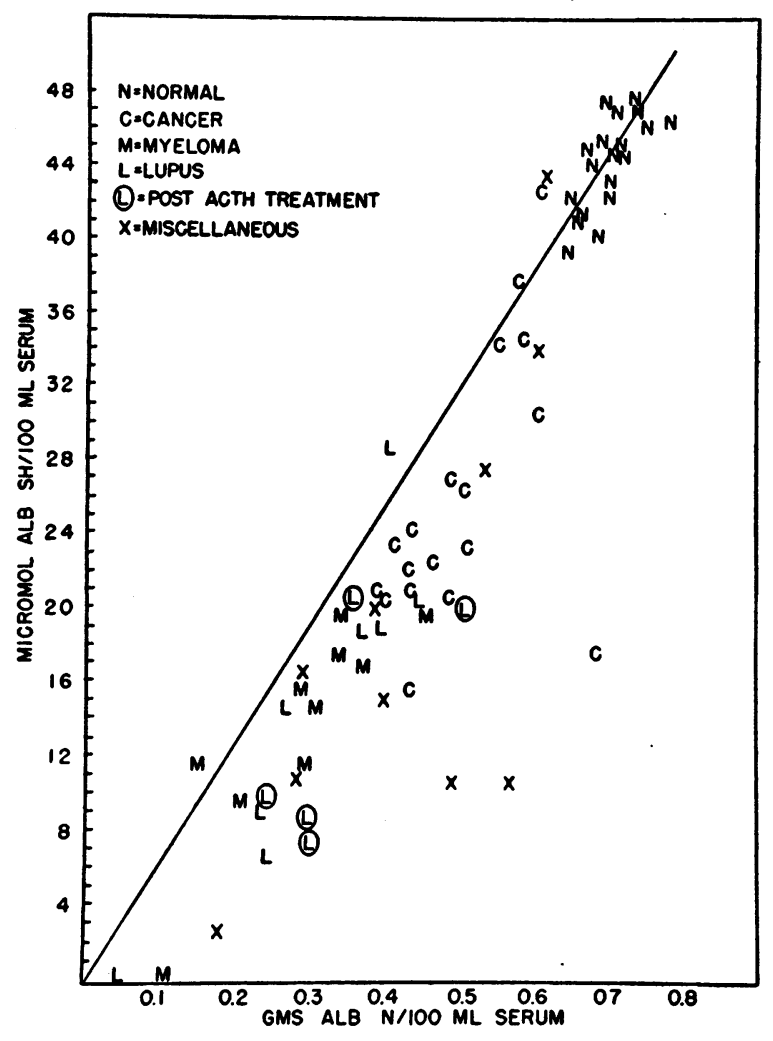

Fig. 12. Distribution of the Albumin SH per Gram of Nitrogen among Patients with Disease

min and globulin $\mathrm{SH}$ values whether expressed as $\mathrm{SH}$ per gram of nitrogen or per peptide unit. The skewness of these observations is in marked contrast to those for the peptide per nitrogen index described previously $\left(\frac{\mathrm{D}}{\mathrm{mg} \text { nitrogen }}\right)$. The albumin fraction in these sera was low both in terms of protein nitrogen and sulfhydryl. The relationship between the albumin $\mathrm{SH}$ values and the albumin nitrogen content is graphically presented in Figure 12. It will be noted that the $\mathrm{SH}$ in the albumin fraction was reduced below the normal range in all sera except for one patient with a melanocarcinoma (Table III, No. 11) and one patient with cystinuria (Table VI, No. 9). The ratio of sulfhydryl to nitrogen was generally reduced below that obtained with normal sera.

These observations indicate that in diseased states, irrespective of the increase or decrease in protein content, a qualitative change occurs in the sulfhydryl content of the serum protein components. The changes in both albumin and globu- lin sulfhydryl are in the same direction and may be the manifestation of a similar alteration in protein synthesis or rearrangement of molecular architecture. No distinctive abnormality, characteristic for the different disease processes, was apparent.

Further study of tissue components and serum fractions is being conducted in the hope that the mechanism responsible for the metabolic abnormality which results in the altered protein sulfhydryl observed in various disease states may be described.

\section{SUMMARY}

1. The sera from patients with malignant tumors, lupus erythematosus, multiple myeloma, and miscellaneous diseases associated with abnormality of the serum proteins have been investigated with respect to the albumin and globulin content as measured by the protein nitrogen, biuret method and electrophoresis.

2. The sulfhydryl content of the serum protein as well as of the albumin and globulin components has been determined employing an amperometric titration technique.

3. A reduction in the albumin component with normal or increased globulin has been observed in these sera but the peptide per mg of nitrogen did not deviate markedly from the normal.

4. The sulfhydryl per $\mathrm{mg}$ of protein nitrogen or per peptide bond was subnormal in both the albumin and globulin components in $75 \%$ of these sera.

5. It is believed that a metabolic abnormality related to protein formation exists in these disease states which is reflected in the low sulfhydryl values in the albumin and globulin fractions.

6. The changes in the serum protein and the sulfhydryl values in patients who received ACTH or folic acid antagonist therapy are presented. The number was too small for generalization with respect to the mechanism of action of these agents.

\section{ACKNOWLEDGMENTS}

We wish to thank Drs. A. McGehee Harvey, John E. Howard, Sherman M. Mellinkoff, Francis P. Chinard, Ezra M. Greenspan, Jacob Colsky, Stanton Eversole, and B. Abeshouse for their cooperation and aid in these investigations. 


\section{REFERENCES}

1. Gutman, A. B., The plasma proteins in disease, in Advances in Protein Chemistry, edited by Anson, M. L., and Edsall, J. T. Academic Press, Inc., New York, 1948, Vol. 4, p. 155.

2. Hopkins, F. G., On an autoxidisable constituent of the cell. Biochem. J., 1921, 15, 286.

3. Dickens, F., Interaction of halogenacetates and $\mathrm{SH}$ compounds. The reaction of halogenacetic acids with glutathione and cysteine. The mechanism of iodoacetate poisoning of glyoxylase. Biochem. J., 1933, 27, 1141.

4. Cori, C. F., Cori, G. T., and Green, A. A., Crystalline muscle phosphorylase. III. Kinetics. J. Biol. Chem., 1943, 151, 39.

5. Hellerman, L., Chinard, F. P., and Deitz, V. R., Protein sulfhydryl groups and the reversible inactivation of the enzyme urease. The reducing groups of egg albumin and of urease. J. Biol. Chem., 1943, 147, 443.

6. Barron, E. S. G., and Singer, T. P., Sulfhydryl enzymes in carbohydrate metabolism. J. Biol. Chem., 1945, 157, 221.

7. Rapkine, L., Sur les processus chimiques au cours de la division cellulaire. Ann. de physiol., 1931, 7, 382.

8. Brachet, J., The localization and the role of ribonucleic acid in the cell. Ann. N. Y. Acad. Sc., 1950, 50 , art. 8, 861.

9. Harris, L. J., On the existenee of an unidentified sulphur grouping in the protein molecule. I. On the denaturation of proteins. Proc. Roy. Soc. London, Series B, 1923, 94, 426.

10. Chibnall, A. C., Amino-acid analysis and the structure of proteins. Proc. Roy. Soc. London, Series B, 1943, 131, 136.
11. Greenstein, J. P., Sulfhydryl groups in proteins. I. Egg albumin in solutions of urea, guanidine, and their derivatives. J. Biol. Chem., 1938, 125, 501.

12. Schoenbach, E. B., Armistead, E. B., and Weissman, $\mathrm{N}$., The sulfhydryl content of normal and abnormal human sera. Proc. Soc. Exper. Biol. \& Med., 1950, 73, 44.

13. Weissman, N., Schoenbach, E. B., and Armistead, E. B., The determination of sulfhydryl groups in serum. I. Methods and results on normal sera. J. Biol. Chem., 1950, 187, 153.

14. Pillemer, L., and Hutchinson, M. C., The determination of the albumin and globulin contents of human serum by methanol precipitation. J. Biol. Chem., 1945, 158, 299.

15. Brand, E., Amino acid composition of simple proteins. Ann. N. Y. Acad. Sc., 1946, 47, 187.

16. Mider, G. B., Alling, E. L., and Morton, J. J., The effect of neoplastic and allied diseases on the concentration of the plasma proteins. Cancer, 1950, 3, 56.

17. Kolthoff, I. M., and Lingane, J. J., Polarography. Interscience Publishers, Inc., New York, 1946.

18. Black, M. M., Sulfhydryl reduction of methylene blue with reference to alterations in malignant neoplastic disease. Cancer Res., 1947, 7, 592.

19. Glass, G. B. Jerzy, Defective thermal coagulation of blood serum in cancer and other diseases and its clinical interpretation. J. Mt. Sinai Hosp., 1950, $17,1$.

20. Huggins, C., Cleveland, A. S., and Jensen, E. V., Thermal coagulation of serum in diagnosis. J.A.M.A., 1950, 143, 11.

21. Huggins, C., Miller, G. M., and Jensen, E. V., Thermal coagulation of serum proteins. II. Deficient coagulation in cancer and the iodoacetate index. Cancer Res., 1949, 9, 177. 